\title{
Correction to: Factors influencing childhood anaemia in Bangladesh: a two level logistic regression analysis
}

Abu Yusuf', A. S. M. A. Mamun', Md. Kamruzzaman', Aik Saw², Nagah M. Abo El-fetoh³, Pete E. Lestrel ${ }^{4}$ and Md. Golam Hossain ${ }^{1 *}$

\section{Correction to: BMC Pediatr https://doi.org/10.1186/s12887-019-1581-9}

Following publication of the original article [1], the authors reported that one name in the published online version was incorrect - Golam Hussain should have been Md. Golam Hossain. The corrected name is now provided in the author group section above and the name has been corrected in the original article.

\begin{abstract}
Author details
${ }^{1}$ Health Research Group, Department of Statistics, University of Rajshahi, Rajshahi 6205, Bangladesh. ${ }^{2}$ National Orthopaedic Centre of Excellence for Research and Learning (NOCERAL), Department of Orthopaedic Surgery, University of Malaya, Kuala Lumpur, Malaysia. ${ }^{3}$ Department of Community Medicine, Faculty of Medicine, Sohag University, Sohag, Egypt. ${ }^{4}$ Sections of Orthodontics and Oral Biology, School of Dentistry, University of California, Los Angeles, California, USA.
\end{abstract}

Published online: 26 July 2019

\section{Reference}

1. Yusuf A, Mamun ASMA, Kamruzzaman M, Saw A, El-fetoh NMA, Lestrel PE,

Hossain G. Factors influencing childhood anaemia in Bangladesh: a two

level logistic regression analysis. BMC Pediatr. 2019; https://doi.org/10.1186/ s12887-019-1581-9.

\footnotetext{
*Correspondence: hossain95@yahoo.com

${ }^{1}$ Health Research Group, Department of Statistics, University of Rajshahi,

Rajshahi 6205, Bangladesh

Full list of author information is available at the end of the article
} 